\title{
Estimated genetic parameters for all genetically evaluated traits in Canadian Holsteins
}

\author{
G. A. Oliveira Junior, ${ }^{1 *}$ F. S. Schenkel, ${ }^{1}$ L. Alcantara, ${ }^{1}$ K. Houlahan, ${ }^{1}$ C. Lynch, ${ }^{1}$ and C. F. Baes ${ }^{1,2}$ \\ ${ }^{1}$ Centre for Genetic Improvement of Livestock, Department of Animal Biosciences, University of Guelph, Guelph, ON, N1G 2W1, Canada \\ ${ }^{2}$ Institute of Genetics, Department of Clinical Research and Veterinary Public Health, University of Bern, Bern, 3001, Switzerland
}

\section{ABSTRACT}

Genetic improvement is a crucial tool to deal with the increasing demand for high quality, sustainably produced dairy. Breeding programs are based on genetic parameters, such as heritability and genetic correlations, for economically important traits in a population. In this study, we estimated population genetic parameters and genetic trends for 67 traits evaluated on heifers and first-lactation Canadian Holstein cows. The data consisted of approximately 500,000 records with pedigree information collected from 1980 to 2019 . Genetic parameters were estimated using bivariate linear animal models under a Bayesian approach. Analyses for the 67 traits resulted in 2,211 bivariate combinations, from which the estimated genetic parameters are reported here. The most highly heritable traits were fat percent (0.66) and protein percent (0.69), followed by stature $(0.47)$. Lowest heritabilities $(0.01)$ were observed for disease-related traits, such as lameness and toe ulcer, and calf survival. The genetic correlations between gestation length, calf size, and calving ease measured on both heifer and cows were close to unity. On the other hand, traits such as body condition score and pin width, cystic ovaries and sole ulcer, rear teat placement, and toe ulcer were genetically unrelated. This study reports genetic parameters that have not been previously published for Canadian Holstein cows, and provides updates of those previously estimated. These estimates are useful for building new indexes, updating existing selection indexes, and for predicting correlated responses due to inclusion of novel traits in the breeding programs.

Key words: heritability, genetic correlation, genetic trends

Received January 27, 2021.

Accepted March 25, 2021.

*Corresponding author: gerson@uoguelph.ca

\section{INTRODUCTION}

The Canadian dairy industry has approximately 968,700 dairy cows on 10,371 farms. Among these animals, around $64.2 \%$ are enrolled in milk-recording programs, of which $39.8 \%$ are on supervised systems and $24.4 \%$ are on unsupervised systems. The Canadian dairy cattle population consists of 7 main dairy breeds, with $93 \%$ of cows registered as Holstein (Canadian Dairy Information Center, 2019). Demand for dairy products is likely to increase over the coming decades as global population and wealth increases. Although the genetic improvement of livestock has been very successful in increasing productivity, there is still pressure to improve the sustainability of the dairy industry and the traits contributing to it.

In Canada, genetic selection in Holstein cattle has been done through the Lifetime Performance Index, formerly known as Lifetime Profit Index (LPI), since it was introduced in 1991 and, more recently, through an alternative index called Pro $\$$. In the last $20 \mathrm{yr}, 3$ changes were made to LPI's main components; that is, production: durability: health and fertility, shifting their respective emphasis from 57:38:5 (2001) to 54:36:10 (2005), 51:34:15 (2008), and 40:40:20 (2016). The estimation of genetic parameters for economically important traits is a crucial component of animal breeding programs. Miglior et al. (2017) reviewed the development of phenotypes used in the Canadian dairy cattle selection program over time. Genetic parameters related to the Canadian Holstein population have been estimated for production (e.g., Miglior et al., 2007; Loker et al., 2012), conformation (e.g., Van Dorp et al., 2004), fertility (e.g., Jamrozik et al., 2005; Sewalem et al., 2010, Alves et al., 2020), and relatively more novel traits, such as metabolic diseases (e.g., Guarini et al., 2019), hoof health (e.g., Malchiodi et al., 2017) and milk properties (e.g., Nayeri et al., 2020). Martin et al. (2019) looked at the genetic correlation among a subset of 28 traits on Canadian Holstein cows from all trait groups, except hoof health. In addition to the importance of re-estimating these parameters using current data, a study involving all current routinely recorded 
traits in Canada has not yet been done. The knowledge of the (co)variance between conventional and relatively more novel traits is critical for updating selection indexes and predicting correlated responses when new traits are integrated in the breeding program. The objective of this study was therefore to estimate the genetic parameters for all 67 current routinely evaluated traits in primiparous Canadian Holstein cows.

\section{MATERIALS AND METHODS}

\section{Data}

Data for 67 traits measured on first-lactation cows and heifers were obtained from Lactanet (Guelph, ON, Canada) and were grouped into 5 categories: production (5), conformation (26), fertility (9), health (9), calving (8), workability (2), and hoof health (8). Trait names, abbreviations and definitions are presented in Table 1, whereas their respective descriptive statistics are presented in Supplemental Table S1 (https://cgil .shinyapps.io/correlations/).

Edits were applied to remove contemporary groups (herds) with fewer than 5 animals, and animal records exceeding 3.5 standard deviations above or below the overall trait mean. Within the health file, additional editing steps were applied separately for each disease according to literature (Koeck et al., 2012b; Jamrozik et al., 2016; Guarini et al., 2019). Milk fever was not included in this study, given its low occurrence in firstlactation cows $(<1 \%)$. The fertility traits included in the analysis were edited as in Jamrozik et al. (2005), and hoof lesions were edited following Malchiodi et al. (2017).

A subset of the data was generated by randomly sampling (sample_n function in R) herds for estimation of (co)variance components and genetic parameter. This resulted in files with about 500,000 animals with records over the past generations on at least 1 trait within each trait category. The birth year of animals with recorded phenotypes ranged from 1980 up to 2018. The final pedigree file comprised more than 14 million animals. Four seasons of calving were defined as January to March, April to June, July to September, and October to December. Age at calving classes included 8 levels $(17-24,25,26,27,28,29,30-31$, >31 mo).

\section{Statistical Models}

Bivariate linear animal models were used to estimated (co)variance components using Bayesian methods via Gibbs sampling in the GIBBS1F90 software (http: //nce.ads.uga.edu/html/projects/programs/Linux/ 32bit/gibbs1f90; Misztal et al., 2002). The software uses noninformative inverse Wishart distribution as a priori distributions for (co)variance components for all dispersion parameters. A single chain with a minimum length of 505,000 was generated, in which the first 5,000 iterations were discarded as burn-in. An initial thinning interval of 10 cycles was used, which was increased when needed to overcome autocorrelation between sampled values. Convergence was monitored by visual inspection of trace plots of variance components. Longer chains were generated when convergence criteria were not achieved.

The linear animal models used are presented in Table 2. In general, the models can be described as follows:

$$
\mathbf{y}=\mathbf{X b}+\mathbf{Z} \mathbf{a}+\mathbf{W h}+\mathbf{e},
$$

where $\mathbf{y}$ is the vector of observations; $\mathbf{b}$ is the vector of fixed effects; $\mathbf{a}$ is the vector of random additive genetic effects; $\mathbf{h}$ is the vector of random herd-year effects; $\mathbf{e}$ is the vector of random residual effects; $\mathbf{X}, \mathbf{Z}$, and $\mathbf{W}$ are design matrices relating observations in $\mathbf{y}$ to factors in the model. The covariance matrix was defined as

$$
\left[\begin{array}{l}
\mathbf{a} \\
\mathbf{h} \\
\mathbf{e}
\end{array}\right] \sim M V N\left[\left(\begin{array}{l}
\mathbf{0} \\
\mathbf{0} \\
\mathbf{0}
\end{array}\right),\left(\begin{array}{ccc}
\mathbf{G} \otimes \mathbf{A} & \mathbf{0} & \mathbf{0} \\
\mathbf{0} & \mathbf{I} \otimes \mathbf{H} & \mathbf{0} \\
\mathbf{0} & \mathbf{0} & \mathbf{I} \otimes \mathbf{R}
\end{array}\right)\right],
$$

where $\mathbf{G}$ is the covariance matrix of random additive genetic effects between traits, $\mathbf{H}$ is the covariance matrix of random herd-year effects between traits, and $\mathbf{R}$ is residual covariance matrix between traits. The $\mathbf{A}$ matrix is the additive genetic relationship matrix; and $\mathbf{I}$ is an identity matrix. The nonlinear (score) traits, were analyzed using a linear model, as literature indicates that analyzing these traits with a linear model does not affect model fit and has little effect on the ranking of animals (Negussie et al., 2008; Neuenschwander et al., 2012). Phenotypic correlations $\left(r_{p}\right)$ were estimated as

$$
r_{p}=r_{g} \sqrt{h_{1}^{2} h_{2}^{2}}+r_{h y} \sqrt{h y_{1}^{2} h y_{2}^{2}}+r_{e} \sqrt{e_{1}^{2} e_{2}^{2}},
$$

where, for trait $i, h_{i}^{2}=\sigma_{a i}^{2} / \sigma_{p i}^{2}, \quad h y_{i}^{2}=\sigma_{h y i}^{2} / \sigma_{p i}^{2}$, $e_{i}^{2}=\sigma_{e i}^{2} / \sigma_{p i}^{2}, \quad \sigma_{a i}^{2}=$ additive genetic variance, $\sigma_{h y i}^{2}=$ herd-year variance, $\sigma_{e i}^{2}=$ residual error variance, $r_{g}=$ additive genetic correlation, $r_{e}=$ residual error correlation, $r_{h y}=$ herd-year correlation. The phenotypic variance $\left(\sigma_{p i}^{2}\right)$ was estimated as $\sigma_{a i}^{2}+\sigma_{h y i}^{2}+\sigma_{e i}^{2}$. Both $\sigma_{h y i}^{2}$ and $r_{h y}$ were zero for traits that did not have herd-year effect in their models. For all parameters, posterior 
Table 1. Abbreviations, trait names and their short definitions

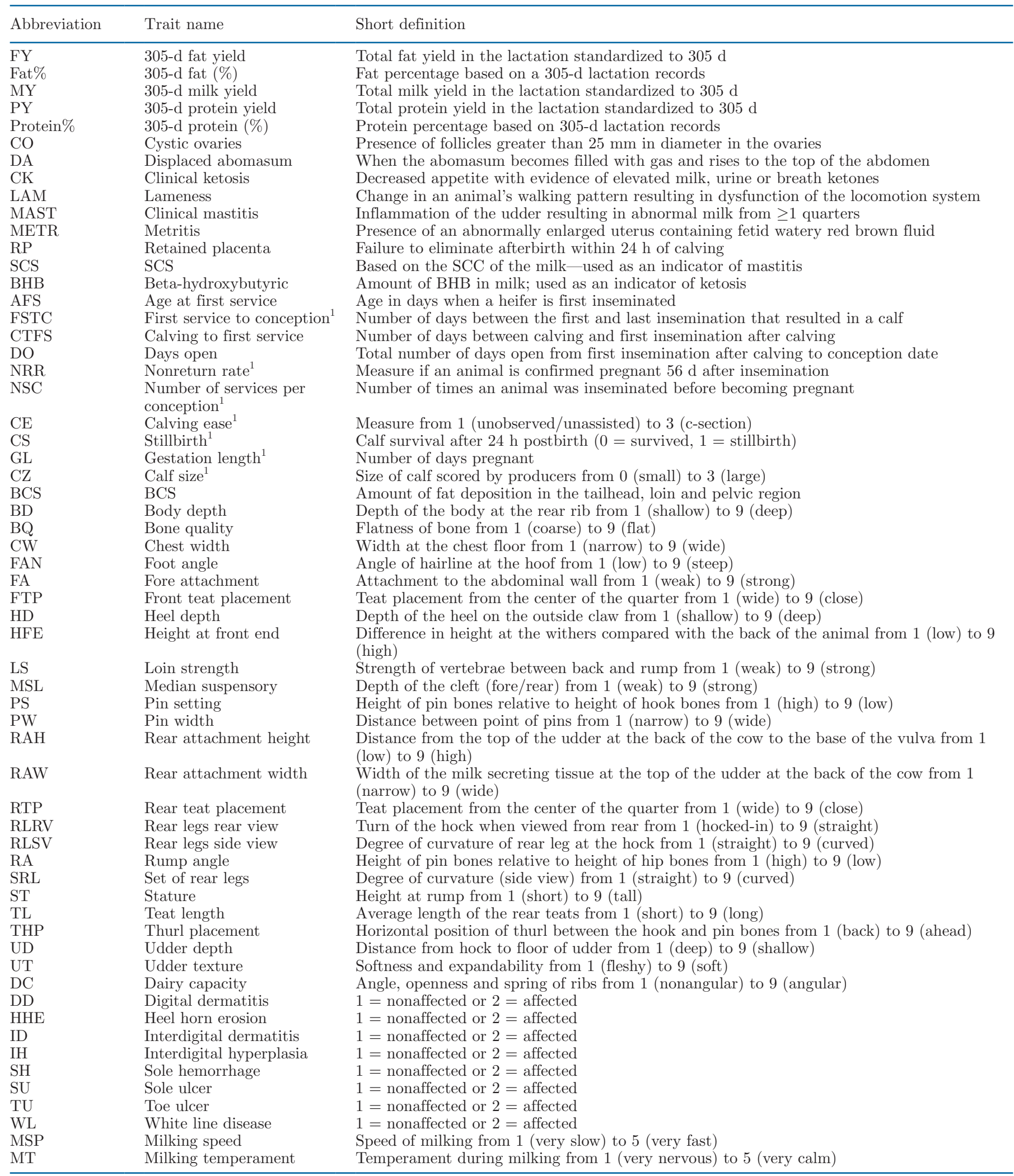

\footnotetext{
${ }^{1}$ Measured in heifers and cows.
} 
mean, posterior standard deviation (PSD), and 95\% highest posterior density were calculated. Genetic trends for bulls, cows, and overall (bulls + cows) were calculated by taking the mean EBV for animals born in a specific year. Only the overall trends will be used when discussing the results.

\section{RESULTS AND DISCUSSION}

Analysis of the 67 traits resulted in 2,211 bivariate combinations. The descriptive statistics, as well as the posterior variance components and genetic trends, are available online: https://cgil.shinyapps.io/correlations/. Supplemental Tables S1 to S7 show the descriptive statistics, posterior mean, PSD, and the $95 \%$ highest posterior density of the estimated parameters. As previously mentioned, knowledge of genetic parameters is crucial for animal breeding programs, not only for best linear unbiased prediction, but also to predict genetic gain, indirect selection response, and to build and update selection indexes. Given the plethora of results produced by this project, the authors chose only to discuss genetic parameters. All correlations reported herein therefore refer to genetic correlations, unless otherwise stated. The reported heritability values are the mean of all estimated heritabilities for a given trait. Trait initials are defined again in the text to facilitate the reader's understanding.

Heritability, as well as genetic correlations, are based on similarity among relatives, quantified by pedigree information (Falconer, 1981). Heritability measures the expected proportion of the differences in performance due to additive genetic effects (narrow-sense heritability). Higher values indicate a higher relationship between the performance of parents and offspring for a given trait. On the other hand, low heritable traits mean that an animal's performance is less useful in identifying the individual's breeding value for the trait. Pedigree errors and data noise can bias heritability estimations downwards, whereas the reduction of environmental and residual components increases the accuracy of heritability estimates. A precise definition and improved consistency in measurements is a way to reduce data noise. It is worth emphasizing that low heritability does not necessarily imply a lack of genetic variability (Berry et al., 2019). In addition, even though some traits present low heritabilities $(<0.05)$, they might have sufficient genetic variance and high economic value, justifying selection for these traits.

When selecting for new traits, it is essential to remember that even though it is possible to intensely select for a single trait, consideration must be given to the genetic correlations that exist with other economi- cally important traits. The genetic correlation expresses the magnitude and direction in which a pair of traits are linearly genetically associated and can be caused either by linkage disequilibrium of genes affecting the 2 traits independently or by the pleiotropic effects of single genes. Traits could be phenotypically correlated but not share any genetic background, meaning that the phenotypic correlation is determined solely by the environmental correlation. In this case, selection on one trait has no effect on the response of the other (Walsh and Lynch, 2018). On the other hand, for highly heritability traits, the genetic correlation has the largest contribution to the observed (phenotypic) correlation. The dual nature of phenotypic correlation often makes it a poor approximation of genetic correlations, as even the sign of these correlations may differ (Falconer, 1981). However, differences between phenotypic and genetic correlations may also be a consequence of imprecise estimates of genetic correlations (Cheverud, 1988; Koots and Gibson, 1996). It is important to highlight that traits with an antagonistic relationship (e.g., production and fertility) can still be improved simultaneously through selection. The inclusion of antagonistic traits in a selection index may reduce the rate of genetic gain in either trait due to a reduction in selection intensity; however, genetic gain is still possible in both traits (Berry, 2013).

Genetic selection aims to change the population mean genotypic value and, consequently, the observed phenotypes. This shift of the mean is caused by very small changes in allele frequency over the genome under a polygenic model. This change in allele frequency is cumulative and permanent (Walsh and Lynch, 2018). Changes in allele frequency are also expected to affect genetic correlation (Bohren et al., 1966). Given that selection can cause changes in correlation values over time, there is a need to frequently re-estimate these parameters.

Divergence in genetic parameters among studies are likely related to the differences in data structure, statistical models, and the population sampled. Koots and Gibson (1996) stated that variation in estimated genetic parameters for different populations can be also related to poor estimation of residual variances. Although genomic information was not included in this study, Forni et al. (2011) and Veerkamp et al. (2011) found that estimates by REML and single-step genomic REML (ssGBLUP) were similar, with ssGBLUP resulting in smaller standard errors due to the inclusion of genomic information. Cesarani et al. (2019), working with simulated data, also reported similar results between REML and ssGBLUP, depending on the genotyping strategy applied. 
Oliveira Junior et al.: GENETIC PARAMETERS OF EVALUATED TRAITS

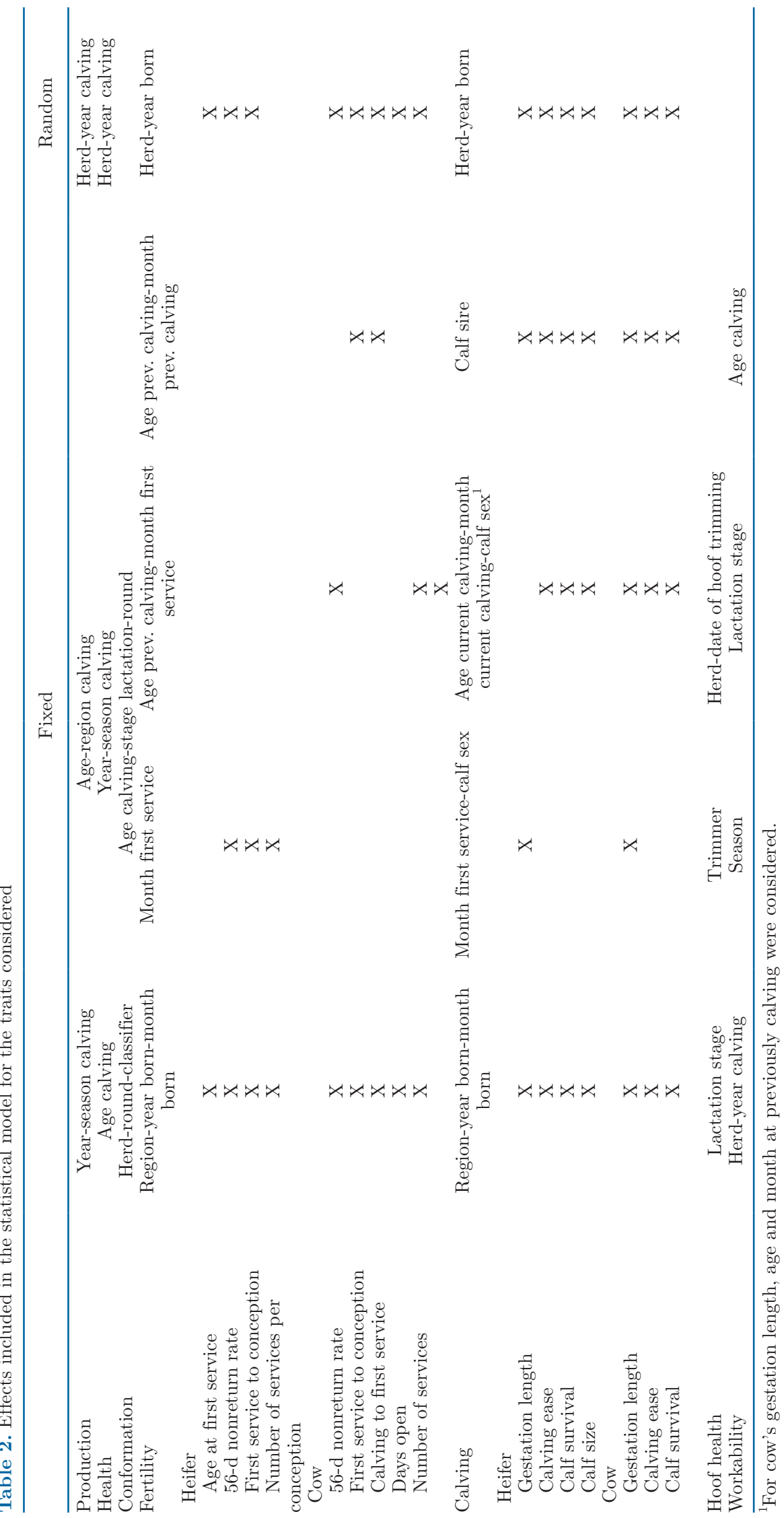


Table 3. The posterior mean ${ }^{1}$ of the genetic correlation (above diagonal), heritability (diagonal), and phenotypic correlation (below diagonal) for production traits ${ }^{2}$

\begin{tabular}{lrcrrr}
\hline Item & Fat\% & FY & MY & Protein\% & \multicolumn{1}{c}{ PY } \\
\hline Fat\% & $\mathbf{0 . 6 6}$ & 0.49 & -0.52 & 0.66 & -0.22 \\
FY & 0.36 & $\mathbf{0 . 3 1}$ & 0.48 & 0.09 & 0.64 \\
MY & -0.29 & 0.46 & $\mathbf{0 . 3 3}$ & -0.57 & 0.86 \\
Protein\% & 0.50 & 0.07 & -0.32 & $\mathbf{0 . 6 8}$ & -0.08 \\
PY & -0.14 & 0.81 & 0.59 & 0.08 & $\mathbf{0 . 2 4}$ \\
\hline
\end{tabular}

${ }^{1}$ Posterior standard deviations (PSD) for heritability estimates varied from 0.0013 to 0.0014 , whereas for genetic and phenotypic correlations, they varied from 0.0009 to 0.0030 and 0.0002 to 0.0008 , respectively. Individual PSD are given in Supplemental Table S2 (https://cgil.shinyapps.io/correlations/).

${ }^{2} \mathrm{Fat} \%=$ fat percentage, $\mathrm{FY}=$ fat yield, $\mathrm{MY}=$ milk yield, protein $\%=$ protein percentage, $\mathrm{PY}=$ protein yield.

\section{Heritability}

Production. Heritably estimates of production traits varied from 0.24 protein yield $(\mathbf{P Y})$ to 0.68 (protein \%; Table 3). Similar results were reported by Jamrozik and Schaeffer (1997), with heritabilities of 0.32, 0.28 , and 0.28 for milk yield (MY), fat yield (FY), and PY, respectively. Likewise, Kadarmideen et al., (2003) reported heritabilities of $0.28,0.21$ and 0.19 for MY, FY, and PY, respectively. Cassell (2009), working with US Holstein cattle, estimated heritability of 0.30 for yield traits (milk, fat, protein) and 0.58 and 0.43 for fat percentage and protein percentage, respectively. Although yield trait heritabilities were similar to the ones estimated in our study, higher estimated values were found for fat percentage and protein percentage. As already discussed, these divergences are expected, given the different statistical models and populations used in each study.

Conformation. Conformation trait results were divided into 4 groups based on the scorecard sections established by Holstein Canada (www.holstein.ca), and included mammary system, feet and legs, dairy strength, and rump. There are currently 26 confor- mation traits being genetically evaluated in Canada, which are recorded by Holstein classifiers with a 1 to 9 linear score, except for pin width $(\mathbf{P W})$, rear attachment height, rear attachment width, stature (ST), teat length, udder depth, which are measured in centimeters. Body condition score and rump angle are also recorded differently, with a 1 to 5 score and in angles, respectively. Although these 8 traits are transformed into a 1 to 9 linear score for the national genetic evaluations, we considered them on their observed measure or score.

Heritability for conformation traits ranged from 0.04 set of rear legs to 0.47 (ST). Within scorecards, udder depth $(0.41$; mammary system), bone quality $(0.27$; feet and legs), ST (0.47; dairy strength), and rump angle $(0.36$; rump) were the most heritable traits (Tables 4 , $5,6$, and 7$)$.

Fertility. Heritabilities of all fertility traits are given in Table 8. They ranged from 0.01 (first service to conception measured on heifers, nonreturn rate (NRR), NRR measured on heifers, number of services measured on heifers) to 0.06 [calving to first service (CTFS), days open (DO)] and are in line with the literature (Berry et al., 2016; Fleming et al., 2019). Fleming et

Table 4. The posterior mean ${ }^{1}$ of the genetic correlation (above diagonal), heritability (diagonal), and phenotypic correlation (below diagonal) for mammary system traits ${ }^{2}$

\begin{tabular}{lrrrrrrrrr}
\hline Item & \multicolumn{1}{c}{ FA } & \multicolumn{1}{c}{ FTP } & \multicolumn{1}{c}{ MSL } & RAH & RAW & RTP & TL & UD & UT \\
\hline FA & $\mathbf{0 . 2 6}$ & 0.28 & 0.04 & -0.48 & 0.23 & -0.01 & -0.10 & 0.70 & 0.38 \\
FTP & 0.12 & $\mathbf{0 . 2 9}$ & 0.32 & -0.06 & 0.18 & 0.63 & -0.27 & 0.14 & 0.32 \\
MSL & 0.17 & 0.19 & $\mathbf{0 . 1 6}$ & -0.25 & 0.41 & 0.55 & -0.02 & 0.02 & 0.73 \\
RAH & -0.57 & -0.05 & -0.40 & $\mathbf{0 . 2 3}$ & -0.40 & -0.06 & 0.07 & -0.41 & -0.41 \\
RAW & 0.44 & 0.13 & 0.48 & -0.24 & $\mathbf{0 . 1 8}$ & 0.19 & 0.00 & -0.10 & 0.23 \\
RTP & 0.00 & 0.22 & 0.28 & -0.02 & 0.08 & $\mathbf{0 . 3 0}$ & -0.17 & -0.05 & 0.31 \\
TL & -0.02 & -0.10 & 0.01 & 0.00 & 0.03 & -0.07 & $\mathbf{0 . 2 9}$ & -0.13 & -0.05 \\
UD & 0.82 & 0.14 & 0.03 & -0.34 & -0.10 & -0.01 & -0.06 & $\mathbf{0 . 4 1}$ & 0.40 \\
UT & 0.37 & 0.16 & 0.39 & -0.47 & 0.32 & 0.14 & -0.01 & 0.14 & $\mathbf{0 . 1 3}$ \\
\hline
\end{tabular}

${ }^{1}$ Posterior standard deviations (PSD) for heritability estimates varied from 0.0016 to 0.0021 , whereas for genetic and phenotypic correlations, they varied from 0.0040 to 0.0110 and 0.0008 to 0.0030 , respectively. Individual PSD are given in the supplemental Table S2 (https://cgil.shinyapps.io/correlations/).

${ }^{2} \mathrm{FA}=$ fore attachment, FTP $=$ front teat placement, $\mathrm{MSL}=$ median suspensory ligament, $\mathrm{RAH}=$ rear attachment height, RAW $=$ rear attachment width, $\mathrm{RTP}=$ rear teat placement, $\mathrm{TL}=$ teat length, $\mathrm{UD}=\mathrm{udder}$ depth, UT = udder texture. 
Table 5. The posterior mean ${ }^{1}$ of the genetic correlation (above diagonal), heritability (diagonal), and phenotypic correlation (below diagonal) for feet and legs traits ${ }^{2}$

\begin{tabular}{lcrrrrr}
\hline Item & BQ & FAN & HD & RLRV & RLSV & SRL \\
\hline BQ & $\mathbf{0 . 2 7}$ & -0.06 & 0.02 & 0.23 & 0.20 & 0.38 \\
FAN & 0.01 & $\mathbf{0 . 0 8}$ & 0.83 & 0.24 & -0.35 & 0.36 \\
HD & 0.04 & 0.36 & $\mathbf{0 . 0 8}$ & 0.17 & -0.34 & 0.37 \\
RLRV & 0.28 & 0.08 & 0.09 & $\mathbf{0 . 1 1}$ & -0.24 & 0.47 \\
RLSV & 0.13 & -0.07 & -0.07 & -0.16 & $\mathbf{0 . 2 1}$ & -0.33 \\
SRL & 0.17 & 0.08 & 0.10 & 0.23 & -0.07 & $\mathbf{0 . 0 4}$ \\
\hline
\end{tabular}

${ }^{1}$ Posterior standard deviations (PSD) for heritability estimates varied from 0.0013 to 0.0020 , whereas for genetic and phenotypic correlations, they varied from 0.0059 to 0.0140 and 0.0008 to 0.0013 , respectively. Individual PSD are given in Supplemental Table S2 (https://cgil.shinyapps.io/correlations/).

${ }^{2} \mathrm{BQ}=$ bone quality, FAN $=$ foot angle, $\mathrm{HD}=$ heel depth, RLRV $=$ rear legs rear view, RLSV = rear legs side view, $\mathrm{SRL}=$ set of rear legs.

al. (2019) showed that the relative emphasis on fertility traits in selection indices globally was around $15 \%$. One of the 2 current selection indexes in Canada (LPI) attributes $20 \%$ to the "health and fertility" component, which includes "daughter fertility" as a subindex weighted $67 \%$, with the remaining $33 \%$ going toward "mastitis resistance" (Canadian Dairy Network, 2020). Therefore, the weight on fertility traits on LPI is about $13 \%$ and, given this low emphasis and low heritabilities of fertility traits, dairy producers should not expect rapid genetic improvements for these traits in the short term. Miglior et al. (2017) suggested that indicator traits, such as BCS, could be useful when selecting for fertility, given the low heritability and measurement difficulties of current fertility traits.

Calving. Selection for calving traits in Canada started in the yearly 2000s with calving ease (2006) and later calf survival (2007). Although these 2 traits are normally split in direct and maternal contribution, this study focused only on the direct effect. Low heritabilities were estimated for these traits, 0.03 for CE and 0.01 for CS (Table 9). Steinbock et al. (2003) also reported low heritabilities for direct calf survival and calving ease, with values of 0.04 and 0.06 , respectively. Although calving difficulties are costly to dairy produc- ers, the Canadian Dairy Network reported that unassisted calving represented 69 and $74 \%$ of progeny born from heifers and cows, respectively, from 2016 to 2020 . Moreover, the phenotypic trend of having an unassisted calving has increased since 2003 (Fleming et al., 2020).

Gestation length in both heifers and cows had the highest heritability within calving traits, at 0.17 and 0.13 , respectively. Norman et al. (2011) found that an intermediate gestation length was desirable for productive life, calving ease, stillbirth, culling, and days open. In contrast, Jenkins et al., (2016) concluded that the net effect of shortened gestation length is likely to be economically positive for the seasonal calving dairy system of New Zealand.

Health. A national dairy cattle health and disease data management system was implemented in 2007 by the Canadian DHI associations. Recording of disease incidence is done by producers using on-farm herd management software or record books. These records are later collected by the DHI milk-recording technicians at each test-day herd visit and then provided to the region's DHI association. Additionally, health data from producers participating in the Dossier Santé Animale/Animal Health Record program is collected and forwarded to the DHI database by veterinarians.

Table 6. The posterior mean ${ }^{1}$ of the genetic correlation (above diagonal), heritability (diagonal), and phenotypic correlation (below diagonal) for dairy strength traits ${ }^{2}$

\begin{tabular}{lcccrrr}
\hline Item & BCS & BD & CW & DC & HFE & \multicolumn{1}{c}{$\mathrm{ST}^{3}$} \\
\hline BCS & $\mathbf{0 . 2 3}$ & 0.09 & 0.72 & -0.71 & -0.01 & -0.04 \\
BD & 0.05 & $\mathbf{0 . 3 1}$ & 0.57 & 0.45 & 0.30 & 0.16 \\
CW & 0.24 & 0.26 & $\mathbf{0 . 2 0}$ & -0.06 & 0.29 & 0.36 \\
DC & -0.22 & 0.29 & 0.06 & $\mathbf{0 . 1 9}$ & 0.11 & 0.46 \\
HFE & 0.01 & 0.07 & 0.12 & 0.25 & $\mathbf{0 . 2 4}$ & 0.27 \\
ST $^{3}$ & 0.07 & 0.32 & 0.70 & 0.40 & 0.33 & $\mathbf{0 . 4 7}$
\end{tabular}

${ }^{1}$ Posterior standard deviations (PSD) for heritability estimates varied from 0.0019 to 0.0027 , whereas for genetic and phenotypic correlations, they varied from 0.0040 to 0.0064 and 0.0008 to 0.0035 , respectively. Individual PSD are given in Supplemental Table S2 (https://cgil.shinyapps.io/correlations/).

${ }^{2} \mathrm{BD}=$ body depth, $\mathrm{CW}=$ chest width, $\mathrm{DC}=$ dairy capacity, $\mathrm{HFE}=$ height at front end, $\mathrm{ST}=$ stature.

${ }^{3}$ Measured trait. 
Table 7. The posterior mean ${ }^{1}$ of the genetic correlation (above diagonal), heritability (diagonal), and phenotypic correlation (below diagonal) for rump traits ${ }^{2}$

\begin{tabular}{lccrrr}
\hline Item & LS & PS & PW $^{3}$ & \multicolumn{1}{c}{ RA $^{3}$} & \multicolumn{1}{c}{ THP } \\
\hline LS & $\mathbf{0 . 2 0}$ & 0.53 & 0.10 & 0.42 & 0.38 \\
PS & 0.15 & $\mathbf{0 . 0 7}$ & 0.07 & 0.69 & 0.69 \\
PW $^{3}$ & 0.07 & 0.05 & $\mathbf{0 . 3 2}$ & -0.03 & 0.00 \\
RA $^{3}$ & 0.19 & 0.15 & -0.02 & $\mathbf{0 . 3 6}$ & -0.95 \\
THP $^{2}$ & 0.22 & 0.18 & 0.10 & -0.87 & $\mathbf{0 . 2 2}$ \\
\hline
\end{tabular}

${ }^{1}$ Posterior standard deviations (PSD) for heritability estimates varied from 0.0015 to 0.0030 , whereas for genetic and phenotypic correlations, they varied from 0.0022 to 0.0108 and 0.0010 to 0.0022 , respectively. Individual PSD are given in Supplemental Table S2 (https:// cgil.shinyapps.io/correlations/).

${ }^{2} \mathrm{LS}=$ loin strength, $\mathrm{PS}=$ pin setting, $\mathrm{PW}=$ pin width, $\mathrm{RA}=$ rump angle, THP $=$ thurl placement.

${ }^{3}$ Measured trait.

All data are stored in the national database at the Canadian Dairy Network (Koeck et al., 2012b). In 2016, approximately $40 \%$ of all herds enrolled on DHI milk-recording programs participated in the voluntary health-recording system (Beavers and Van Doormaal, 2016). These records provide a means of tracking health information for dairy producers and their veterinarians to improve herd management and are used in the national genetic evaluation system for genetic selection of disease resistance.

Among the 9 health-related traits, BHB had the highest heritability (0.21), followed by SCS (0.13) and displaced abomasum (DA; 0.04). The lowest heritabilities (0.01) were observed for cystic ovaries (CO), metritis (METR), and lameness (LAM; Table 10). The heritabilities were similar to the literature (Koeck et al., 2012a,b, 2014; Guarini et al., 2019). However, given the categorical outcome of disease traits, heritability estimates on the linear scale are frequency dependent, making direct comparison of values from different studies impossible. Mean incidences of clinical mas- titis (MAST), METR, retained placenta (RP), CO, clinical ketosis (CK), DA, and LAM were 10.3, 8.4, 5.4, 7.1, 5.1, 2.5, and 7.9\%, respectively. Even though metabolic diseases are heavily influenced by management, Lactanet has been publishing genetic evaluation for metabolic disease resistance since 2016. It is worth highlighting that traits such as CK are only measured on visibly ill cows and have a low recording rate (Beavers and Van Doormaal, 2016).

Hoof Health. Hoof health-related traits had heritability estimates ranging from 0.01 [toe ulcer (TU) and interdigital dermatitis (ID)] to 0.11 digital dermatitis (DD; Table 11) and followed values reported in the literature (Malchiodi et al., 2017, 2020; Heringstad et al., 2018). Genetic evaluation for hoof health traits started in 2018 in Canada, after a successful research project that spanned from 2014 to 2017. The most prevalent lesion in the data set was DD (30.2\%), followed by sole hemorrhage $(8.3 \%)$, sole ulcer (SU; $6.2 \%)$, white line disease $(4.2 \%)$, ID $(3.4 \%)$, heel horn erosion $(2.8 \%)$, interdigital hyperplasia (IH; 2.1\%), and TU (1.1\%). Malchiodi et al. (2017) noted that these lesion frequencies may be overestimated because they are only based on cows presented to the hoof trimmers, where some animals might be preferentially chosen for trimming.

Workability. In the workability group of traits, milking speed and milking temperament had heritability estimates of $0.16 \pm 0.01$ and $0.07 \pm 0.01$, respectively. Previously reported heritability estimates of milking speed ranged between 0.11 and 0.42 (Meyer and Burnside, 1987; Boettcher et al., 1998; Hayes, 1998; Lassen and Mark, 2008; Sewalem et al., 2011; Kramer et al., 2013), and between 0.04 and 0.18 for milking temperament (Sewalem et al., 2002, 2011; Lassen and Mark, 2008; Kramer et al., 2013).

Milking temperament is subjectively recorded by producers, where the relative temperament of each cow

Table 8. The posterior mean ${ }^{1}$ of the genetic correlation (above diagonal), heritability (diagonal), and phenotypic correlation (below diagonal) for fertility traits ${ }^{2}$

\begin{tabular}{lrrrrrrrrr}
\hline Item & AFS & CTFS & \multicolumn{1}{c}{ DO } & FSTC & FSTCh & NRR & NRRh & NSC & NSCh \\
\hline AFS & $\mathbf{0 . 0 5}$ & 0.39 & 0.22 & 0.08 & 0.17 & 0.21 & 0.11 & -0.03 & 0.05 \\
CTFS & 0.15 & $\mathbf{0 . 0 6}$ & 0.88 & 0.60 & 0.15 & 0.07 & 0.08 & 0.20 & 0.10 \\
DO & 0.01 & 0.45 & $\mathbf{0 . 0 6}$ & 0.88 & 0.35 & -0.43 & -0.12 & 0.72 & 0.25 \\
FSTC & -0.03 & -0.07 & 0.66 & $\mathbf{0 . 0 3}$ & 0.62 & -0.85 & -0.48 & 0.97 & 0.62 \\
FSTCh & -0.04 & -0.05 & -0.01 & 0.02 & $\mathbf{0 . 0 1}$ & -0.65 & -0.84 & 0.71 & 0.97 \\
NRR & 0.05 & 0.08 & -0.33 & -0.50 & -0.03 & $\mathbf{0 . 0 1}$ & 0.66 & -0.94 & -0.68 \\
NRRh & 0.06 & 0.02 & 0.01 & -0.01 & -0.53 & 0.03 & $\mathbf{0 . 0 1}$ & -0.57 & -0.94 \\
NSC & -0.04 & -0.08 & 0.73 & 0.87 & 0.03 & -0.62 & -0.02 & $\mathbf{0 . 0 3}$ & 0.66 \\
NSCh & -0.05 & -0.04 & -0.02 & 0.02 & 0.87 & -0.04 & -0.65 & 0.04 & $\mathbf{0 . 0 1}$ \\
\hline
\end{tabular}

${ }^{1}$ Posterior standard deviations (PSD) for heritability estimates varied from 0.0005 to 0.0016 , whereas for genetic and phenotypic correlations, they varied from 0.0020 to 0.0379 and 0.0001 to 0.0260 , respectively. Individual PSD are given in Supplemental Table S2 (https://cgil.shinyapps.io/correlations/).

${ }^{2} \mathrm{AFS}=$ age at first service, $\mathrm{CTFS}=$ calving to first service, $\mathrm{DO}=$ days open, $\mathrm{FSTC}=$ first service to conception, $\mathrm{NRR}=$ nonreturn rate, $\mathrm{NSC}=$ number of services per conception, $\mathrm{h}=$ trait measured on heifers. 
Table 9. The posterior mean ${ }^{1}$ of the genetic correlation (above diagonal), heritability (diagonal), and phenotypic correlation (below diagonal) for calving traits ${ }^{2}$

\begin{tabular}{lcccccccc}
\hline Item & CZ & CZh & CE & CEh & GL & GLh & CS & CSh \\
\hline CZ & $\mathbf{0 . 0 5}$ & 1.00 & 0.62 & 0.56 & 0.14 & 0.49 & -0.15 & -0.01 \\
CZh & 1.00 & $\mathbf{0 . 0 8}$ & 0.56 & 0.57 & 0.48 & 0.45 & -0.01 & -0.06 \\
CE & 0.15 & 0.15 & $\mathbf{0 . 0 3}$ & 1.00 & 0.05 & 0.04 & -0.49 & -0.54 \\
CEh & 0.15 & 0.26 & 1.00 & $\mathbf{0 . 1 0}$ & 0.22 & 0.19 & -0.54 & -0.55 \\
GL & 0.23 & 0.22 & 0.04 & 0.04 & $\mathbf{0 . 1 3}$ & 1.00 & -0.09 & -0.03 \\
GLh & 0.22 & 0.20 & 0.03 & 0.06 & 1.00 & $\mathbf{0 . 1 7}$ & 0.03 & -0.01 \\
CS & 0.05 & 0.05 & -0.10 & -0.10 & 0.13 & 0.12 & $\mathbf{0 . 0 1}$ & 0.74 \\
CSh & 0.05 & -0.05 & -0.10 & -0.17 & 0.12 & 0.06 & 0.03 & $\mathbf{0 . 0 7}$ \\
\hline
\end{tabular}

${ }^{1}$ Posterior standard deviations (PSD) for heritability estimates varied from 0.0005 to 0.0029 , whereas for genetic and phenotypic correlations, they varied from 0.0001 to 0.0465 and 0.0001 to 0.0009 , respectively. Individual PSD are given in Supplemental Table S2 (https://cgil.shinyapps.io/correlations/).

${ }^{2} \mathrm{CZ}=$ calf size, $\mathrm{CE}=$ calving ease, $\mathrm{GL}=$ gestation length, $\mathrm{CS}=$ calving survival, $\mathrm{h}=$ trait measured on heifers.

during milking is usually observed during the first 6 mo of their first lactation. Animals are classified in 5 categories, with $1.3 \%$ classified as "very nervous," 9.7\% "nervous," 51.5\% "average," 33.6\% "calm," and 3.9\% "very calm" in the data set. Milking speed is recorded similarly, and showed frequencies of 2.0, 10.7, 62.7, 22.5 , and $2.1 \%$ for "very slow," "slow," "average," "fast," and "very fast," respectively.

\section{Genetic Correlation Within Trait Groups}

Regarding production traits, the 5 highest genetic correlations were observed for MY and PY (0.86 \pm $0.01)$, Fat $\%$ and Protein $\%(0.66 \pm 0.01), F Y$ and PY $(0.64 \pm 0.01), \mathrm{MY}$ and Protein\% $(-0.57 \pm 0.01)$, and FY and Fat\% (0.49 \pm 0.01; Table 3). Cai et al. (2020) also reported high genetic correlations between MY and PY (0.78), FY and MY (0.40), and FY and PY (0.56). Likewise, Kadarmideen et al. (2003) and Martin et al. (2019) reported similar results as in this study.

Among the 26 conformation traits, the highest genetic correlations were observed for RA and thurl placement (THP; $0.95 \pm 0.01)$, FAN and HD $(0.83 \pm$ $0.01)$, UT and MSL $(0.72 \pm 0.01)$, BCS and CW $(0.72$ $\pm 0.01)$, BCS and DC $(-0.71 \pm 0.01)$. Rump angle measures the height of pin bones relative to the height of hip bones, whereas THP measures the position of the thurl between the hook and pin bones. Therefore, the high negative correlation between them $(-0.95 \pm$ 0.01) was expected, whereby a thurl placed too far back would increase the rump angle (lower pin bones). A positive correlation $(0.83 \pm 0.01)$ between FAN and HD was also expected given the nature of the traits, because the lower the angle of the hairline, the shallower the depth of heel will be. Interestingly, RLSV was moderately correlated with both FAN $(-0.35 \pm$ $0.01)$ and HD $(-0.34 \pm 0.01)$, suggesting that a curved leg would contribute to a deeper FAN and shallower HD. Median suspensory ligament was positively correlated with UT $(0.73 \pm 0.01)$, indicating that a softer and more expandable udder is expected in cows with a stronger MSL. Body condition score had similar correlations values with $\mathrm{CW}(0.72 \pm 0.01)$ and $\mathrm{DC}(-0.71 \pm$ 0.01), suggesting that animals with higher BCS would

Table 10. The posterior mean ${ }^{1}$ of the genetic correlation (above diagonal), heritability (diagonal), and phenotypic correlation (below diagonal) for health traits ${ }^{2}$

\begin{tabular}{|c|c|c|c|c|c|c|c|c|c|}
\hline Item & ВHB & CK & MAST & $\mathrm{CO}$ & DA & LAM & METR & $\mathrm{RP}$ & SCS \\
\hline CK & 0.12 & 0.02 & 0.22 & 0.14 & 0.61 & 0.27 & 0.14 & 0.13 & 0.34 \\
\hline MAST & 0.01 & 0.01 & 0.02 & 0.17 & 0.20 & 0.25 & 0.28 & 0.14 & 0.76 \\
\hline DA & 0.05 & 0.21 & 0.01 & 0.01 & 0.04 & 0.14 & 0.31 & 0.12 & 0.18 \\
\hline LAM & 0.01 & 0.01 & 0.02 & 0.00 & 0.01 & 0.01 & 0.10 & 0.09 & 0.27 \\
\hline METR & 0.01 & 0.07 & 0.01 & 0.02 & 0.06 & 0.01 & 0.01 & 0.81 & 0.28 \\
\hline
\end{tabular}

${ }^{1}$ Posterior standard deviations (PSD) for heritability estimates varied from 0.0006 to 0.0021 , whereas for genetic and phenotypic correlations, they varied from 0.0067 to 0.0575 and 0.0006 to 0.0024, respectively. Individual PSD are given in Supplemental Table S2 (https://cgil.shinyapps .io/correlations/).

${ }^{2} \mathrm{CK}=$ clinical ketosis, MAST $=$ clinical mastitis, $\mathrm{CO}=$ cystic ovaries, $\mathrm{DA}=$ displaced abomasum, $\mathrm{LAM}=$ lameness, $\mathrm{METR}=$ clinical metritis, $\mathrm{RP}=$ retained placenta. 
Table 11. The posterior mean ${ }^{1}$ of the genetic correlation (above diagonal), heritability (diagonal), and phenotypic correlation (below diagonal) for hoof health traits ${ }^{2}$

\begin{tabular}{lccccccrr}
\hline Item & DD & HHE & ID & IH & \multicolumn{1}{c}{ SH } & SU & \multicolumn{1}{c}{ TU } & WL \\
\hline DD & $\mathbf{0 . 1 1}$ & 0.43 & 0.81 & 0.67 & 0.05 & 0.16 & -0.18 & 0.06 \\
HHE & 0.06 & $\mathbf{0 . 0 2}$ & 0.42 & 0.32 & 0.03 & 0.04 & -0.19 & -0.03 \\
ID & 0.05 & 0.10 & $\mathbf{0 . 0 1}$ & 0.65 & -0.02 & 0.02 & -0.08 & -0.07 \\
IH & 0.11 & 0.02 & 0.05 & $\mathbf{0 . 0 4}$ & 0.05 & 0.14 & -0.31 & 0.01 \\
SH & 0.00 & 0.03 & 0.00 & 0.01 & $\mathbf{0 . 0 3}$ & 0.83 & 0.16 & 0.46 \\
SU & 0.00 & 0.06 & 0.02 & 0.00 & 0.09 & $\mathbf{0 . 0 4}$ & 0.35 & 0.60 \\
TU & -0.03 & 0.00 & 0.00 & -0.01 & 0.02 & 0.05 & $\mathbf{0 . 0 1}$ & 0.41 \\
WL & -0.02 & 0.01 & -0.01 & 0.00 & 0.07 & 0.04 & 0.05 & $\mathbf{0 . 0 2}$ \\
\hline
\end{tabular}

${ }^{1}$ Posterior standard deviations (PSD) for heritability estimates varied from 0.0010 to 0.0039 , whereas for genetic and phenotypic correlations, they varied from 0.0200 to 0.0790 and 0.0020 to 0.0020 , respectively. Individual PSD are given in Supplemental Table S2 (https://cgil.shinyapps.io/correlations/).

${ }^{2} \mathrm{DD}=$ digital dermatitis, $\mathrm{HHE}=$ heel horn erosion, $\mathrm{ID}=$ interdigital dermatitis, $\mathrm{IH}=$ interdigital hyperplasia, $\mathrm{SH}=$ sole hemorrhage, $\mathrm{SU}=$ sole ulcer, $\mathrm{TU}=$ toe ulcer, $\mathrm{WL}=$ white line disease.

have a wider chest, and less angular and sprung ribs. It is interesting to note that each of these correlations are between traits from the same scorecard, and all 4 (scorecards) are represented within the 5 highest genetic correlated traits, reinforcing the importance of balanced conformation in dairy cows.

Among the fertility traits, DO had a correlation of $0.88 \pm 0.01$ with both CTFS and FSTC. The high correlation between NS and FSTC $(0.97 \pm 0.01)$ was expected because lower NS will reduce the FSTC interval for both heifers and cows. Similarly, NRR and FSTC also showed a high correlation of $-0.85 \pm 0.01$ and $-0.84 \pm 0.01$ for cows and heifers, respectively. It is important to highlight that the current fertility traits are highly influenced by management decisions and human errors, such as: voluntary waiting periods, data-recording errors or failure to record events, failure to detect estrus, mismanagement (e.g., inseminating animals at an inappropriate time of the estrous cycle), and unrecorded management decisions (e.g., unrecorded hormonal synchronization treatments; Berry et al., 2016; Oliveira Junior et al., 2021).

With the exception of calf survival, no genetic difference was observed between calving traits measured on heifers and cows (i.e., correlation equal to one). HaileMariam and Pryce (2019) also reported a high correlation of gestation length measured in heifers and cows. The authors concluded that given the limited data on heifers, a repeatability animal model that uses both heifer and cow data is preferred. Given the moderate correlation between $\mathrm{CZ}$ and $\mathrm{CE}$, and the negative correlation between $\mathrm{CE}$ and $\mathrm{CS}$, it can be concluded that larger calves have a harder birth process and, in turn, poor survival. Calving ease in heifers was highly correlated with both CZh $(0.57 \pm 0.01)$ and CSh $(-0.55 \pm$ 0.01 ), suggesting again that larger calves have harder birth processes and, in turn, reduced survival.
Somatic cell score and MAST showed a high genetic correlation $(0.76 \pm 0.01)$, reinforcing the use of SCS as an indirect means of selection for mastitis resistance. Mastitis was also moderately correlated with METR $(0.28 \pm 0.05)$ and LAM $(0.25 \pm 0.02)$. Retained placenta and METR had an estimated correlation of 0.81 \pm 0.02 , the highest value among health-related traits. Koeck et al. (2012b) also reported high correlation between these 2 traits $(0.62 \pm 0.11)$.

Among hoof health traits, DD was the trait with highest genetic correlation values, specifically with ID $(0.81 \pm 0.03)$ and $\mathrm{IH}(0.67 \pm 0.04)$. Other notable genetic correlations $(\geq 0.60)$ were observed between $\mathrm{SH}$ and SU $(0.83 \pm 0.02)$, ID and IH $(0.65 \pm 0.03)$, and SU and WL $(0.60 \pm 0.03)$. Malchiodi et al. (2017, 2020) also estimated high correlations between the mentioned traits, but with smaller values than the ones reported by this study.

\section{Correlations Among Trait Groups}

Production-Conformation. Not surprisingly, conformation traits in the dairy strength and mammary system scorecards had the highest genetic correlation with production, such as MY and DC (0.54 \pm $0.01)$, PY and DC $(0.52 \pm 0.01), \mathrm{MY}$ and UD $(-0.45$ $\pm 0.01), \mathrm{FY}$ and DC $(0.45 \pm 0.01)$, and PY and UD $(-0.45 \pm 0.01)$. Dairy capacity, which is related to the angle, openness and spring of ribs, was highly positively correlated with MY, FY, and PY. In contrast, UD was negatively correlated with the 3 yield production traits, with FY and UD $(-0.33 \pm 0.01)$ being the strongest correlation.

Production-Fertility. The 10 strongest correlations among production and fertility traits were unfavorable. For example, the correlation between MY and DO was $0.43 \pm 0.01$; therefore, higher breeding values 
for MY are associated with high values for DO, which is not desired. Milk yield was also unfavorably correlated with CTFS $(0.38 \pm 0.01)$, FSTC $(0.38 \pm 0.01)$, and NS $(0.37 \pm 0.01)$. The correlation between PY and DO $(0.41 \pm 0.01)$ was the second highest between these 2 groups of traits.

Production-Health. In general, an unfavorable correlation between production and health traits was observed, with the 5 highest correlations found between: Protein \% and CK $(-0.33 \pm 0.03), \mathrm{MY}-\mathrm{LAM}(0.30 \pm$ $0.03), \mathrm{FY}$ and $\mathrm{CO}(0.30 \pm 0.02), \mathrm{MY}$ and $\mathrm{BHB}(0.30$ $\pm 0.01)$, and FY and CK $(0.30 \pm 0.03)$. The correlation between MY and MAST was $0.29 \pm 0.01$, which is within the literature range of 0.21 to 0.55 (Heringstad et al., 2000), suggesting a higher probability of mastitis in high-production cows.

Production-Hoof Health, Calving, and Workability. The 2 highest genetic correlations estimated between production and hoof health, calving and workability traits were MY and TU $(0.26 \pm 0.05), \mathrm{MY}$ and $\mathrm{SU}(0.26 \pm 0.02), \mathrm{PY}$ and $\mathrm{CZh}(0.18 \pm 0.01), \mathrm{MY}$ and CZh $(0.17 \pm 0.01)$, MY and MT $(0.14 \pm 0.01)$, and PY and MT $(0.12 \pm 0.01)$. Similar to fertility, positive genetic correlations between production and such traits are unfavorable, such that higher MY is associated with higher cases of TU and SU, and consequently with LAM, a health trait also positively correlated with MY $(0.30 \pm 0.03)$.

Conformation-Fertility. In terms of correlations between conformation and fertility traits, DC was positively correlated with DO $(0.48 \pm 0.01)$, FSTC $(0.42$ $\pm 0.01)$, and NS $(0.41 \pm 0.01)$, which suggests that more capacious animals need more services to conceive, therefore having more days between first service to conception and consequently having more open days. These moderate correlations suggest that DC could be a good indicator of fertility performance. A moderately high negative correlation between ST and AFS $(-0.45$ \pm 0.01 ) suggests that animals with faster growth rate are likely to reach puberty early in life (Moore et al., 1990; Bastin and Gengler, 2013). Correlation between BCS and CTFS $(-0.39 \pm 0.01)$ were among the 5 highest correlations found between BCS and other fertility traits, which is in agreement with previously published work by Pryce et al. (2001), who observed genetic correlation between BCS and days to first service ranging from -0.18 to -0.54 . This unfavorable correlation suggests that thinner cows, or cows in greater negative energy balance, tend to have worse fertility performance (Veerkamp and Thompson, 1999; Pryce et al., 2000).

Conformation-Health. High genetic correlations were observed between conformation and health traits, such as BCS and KET $(-0.56 \pm 0.03)$, set of rear legs and LAM $(-0.45 \pm 0.02)$, DC and KET $(0.44 \pm 0.03)$,
BCS and BHB $(-0.37 \pm 0.01)$, and UD and KET $(-0.36 \pm 0.03)$. It is well known that cows with low BCS are more susceptible to metabolic diseases, such as KET (Shin et al., 2015). This agrees with the moderate negative correlation observed between these traits. Dairy capacity and UD also showed moderate genetic correlation with KET, suggesting that higher DC and deeper UD could lead to animals more susceptible to KET. The set of rear legs had a moderate negative correlation with LAM, suggesting that straight legs (side view) could be an indicator of LAM problems.

Conformation-Calving. Estimated correlations between conformation and calving traits also showed interesting results. The 5 highest values were ST and $\mathrm{CZ}(0.52 \pm 0.01), \mathrm{ST}$ and CZh $(0.44 \pm 0.01), \mathrm{CW}$ and $\mathrm{CZ}(0.37 \pm 0.01)$, THP and CS $(0.33 \pm 0.03)$, and PW and $\mathrm{CZ}(0.29 \pm 0.01)$. Stature, CW, and PW appeared to be positively correlated with CZ. These 3 conformation traits (ST, CW, and PW) also showed positive correlation with calving ease $(0.16 \pm 0.02,0.09 \pm 0.01$, $0.14 \pm 0.02$, respectively). This suggests that larger animals are more likely to have calving difficulties. On the other hand, THP was positively correlated with CS, suggesting that higher THP scores could facilitate the calving process.

Conformation-Hoof Health. Feet and leg traits had the highest correlations with hoof health traits. Foot angle and TU were the highest correlated traits $(0.42 \pm 0.06)$, followed by RLRV and ID $(-0.31 \pm$ $0.02)$. Heel depth had a correlation of $-0.28 \pm 0.03$ with IH, SU, and ID. These correlations suggest that indirect selection on hoof health can be done by selection on traits included in the "feet and legs" scorecard.

Fertility-Calving. Calf size on both cows and heifers were negatively correlated with AFS $(-0.50 \pm 0.02$, $-0.45 \pm 0.02$, respectively), suggesting that younger heifers are likely to have bigger calves in comparison with their own size. A negative correlation was found between CS and DO $(-0.29 \pm 0.03)$, suggesting that cows with calving problems leading to stillborn calves are likely to have longer days open intervals. Calf survival in both cows and heifers was also negatively correlated with NS $(-0.30 \pm 0.02$ and $-0.28 \pm 0.02$, respectively), which is in line with the previously mentioned results.

Fertility-Health. Among fertility and health traits, $\mathrm{CO}$ had a correlation of $0.54 \pm 0.03$ with both FSTC and DO. Likewise, METR was also unfavorably correlated with NRR $(-0.47 \pm 0.03)$, FSTC $(0.45 \pm 0.05)$, and NS $(0.45 \pm 0.04)$. This is in agreement with previous research, highlighting that cows affected by any disease are more likely to have problems starting a new estrous cycle, thus requiring more inseminations (Pryce et al., 1997; Pritchard et al., 2013). 
Fertility-Hoof Health. Considering fertility and hoof health traits, TU was positively correlated with NS $(0.35 \pm 0.04)$, DO $(0.31 \pm 0.05)$, and FSTC $(0.28 \pm$ 0.05 ), whereas SU was positively correlated with CTFS $(0.32 \pm 0.04)$, and DO $(0.28 \pm 0.04)$. These unfavorable correlations were expected, because injured animals would allocate additional energy into the recovery process, reducing energy available for reproductive activities.

Workability. The genetic correlation between MSP and MT was $0.18 \pm 0.01$. This estimated correlation is within the literature range, with values ranging from -0.04 (Kramer et al., 2013) to 0.25 (Sewalem et al., 2011). In regard to their correlation with other trait groups, a cow with a calmer temperament would also have less heel horn erosion $(0.27 \pm 0.03)$, easier calving $(0.19 \pm 0.03)$, smaller calf size $(0.19 \pm 0.02)$, less lame $(0.18 \pm 0.04)$, and better dairy capacity $(0.17 \pm 0.01)$. On the other hand, cows that milk more quickly likely have higher SCS $(0.27 \pm 0.01)$, shorter teats $(-0.21$ $\pm 0.01)$, a deeper udder $(0.20 \pm 0.01)$, better udder texture $(0.18 \pm 0.01)$, and fewer toe ulcer problems $(-0.17 \pm 0.05)$.

\section{Genetic Trends}

The Canadian Dairy Network works closely with breed associations when updating their selection index formula emphasizing conformation traits (LPI). In the latest Holstein LPI update (March 2020) weights were kept as $40 \%$ production, $40 \%$ durability, and $20 \%$ health and fertility (www.lactanet.ca). In general, national indexes are updated every few years as market conditions or breed goals evolve. However, if important changes occur in the industry, for example, to favor fat production to an even greater extent, indexes are updated more frequently to reflect such changes.

All production traits showed considerable genetic gain in the whole period of time considered in this study (1980 to 2019). Interestingly, Fat\% had a decrease in its genetic mean from 1993 to 2003, which then returned to an increasing trend. Fertility traits showed an unfavorable genetic trend for all 9 measured traits for several years; however, the trend for DO, CTFS, and FSTC started to flatten around 2002. The NS had a sharp drop in 2011, whereas AFS started to decrease around 1994.

Mammary system conformation traits generally showed positive genetic trends, except for a slight decrease in TL, which was considered favorable, and a more pronounced decrease in rear attachment height since 1990. In the "feet and legs" scorecard, all traits showed a positive genetic trend, highlighting bone quality, which has increased since 1988. Among dairy strength traits, ST had a more pronounced gain, with a positive trend since 1984. Around the same year, a positive trend for DC and a decreasing trend in BCS was observed. Loin strength was the trait with greatest gain among rump traits. Pin setting and THP trends became positive around 1988, whereas RA showed an inconsistent trend, with ups and downs during the analyzed period.

Given the high correlation between GL and GLh, their genetic trends followed similar a pattern, with higher values in 2005 and a decreasing tendency since then. Calf size and CE trends followed a similar pattern of decrease (around 2005), whereas CS values started to increase around 2007. Fleming et al. (2020) observed the phenotypic trend of having an unassisted calving has increased since 2003. It is worth noting that genetic selection on these traits officially started in 2008 with the introduction of "Daughter Calving Ability" and "Calving Ability" selection indexes (Van Doormaal, 2007).

Health traits MAST, CK, METR, and DA showed a decreased trend starting around 2007. Lameness had an increasing trend between 1995 and 2007, with a slight decrease after 2013. On the other hand, CO and BHB had positive trends for the whole studied period. Somatic cell score trend started decreasing around 2003. It is worth mentioning that these health-related traits have a recent selection history, with selection for mastitis resistance starting in 2013 and, later in 2016, for other health-related traits.

Heel horn erosion, ID, and TU trends spiked in 2005, with other hoof health traits trends slightly decreasing after 2008. These trends are a consequence of indirect selection (genetic correlations), given that selection on hoof health traits officially started in 2018. In the group of workability traits, both MSP and MT showed positive trends since around 1986.

\section{CONCLUSIONS}

In this study, we estimated population genetic parameters for 67 currently evaluated traits on heifers and first-lactation Canadian Holstein cows. We report genetic parameters that have not been previously estimated for Canadian Holsteins and update those that have been previously estimated. These estimates are useful for building new indexes, updating existing selection indexes, and for predicting correlated responses due to inclusion of novel traits in the breeding programs.

\section{ACKNOWLEDGMENTS}

This research was financially supported by Agriculture and Agri-Food Canada, and by additional contri- 
butions from Dairy Farmers of Canada, the Canadian Dairy Network and the Canadian Dairy Commission under the Agri-Science Clusters Initiative. As per the research agreement, aside from providing financial support, the funders have no role in the design and conduct of the studies, data collection and analysis, or interpretation of the data. Researchers maintain independence in conducting their studies, own their data, and report the outcomes regardless of the results. The decision to publish the findings rests solely with the researchers. C. F. Baes acknowledges support from the Natural Sciences and Engineering Research Council of Canada (NSERC) Canada Research Chair (CRC) program. The authors confirm that there are no conflicts of interest.

\section{REFERENCES}

Alves, K., L. F. Brito, C. F. Baes, M. Sargolzaei, J. A. B. Robinson, and F. S. Schenkel. 2020. Estimation of additive and non-additive genetic effects for fertility and reproduction traits in North American Holstein cattle using genomic information. J. Anim. Breed. Genet. 137:316-330. https://doi.org/10.1111/jbg.12466.

Bastin, C., and N. Gengler. 2013. Genetics of body condition score as an indicator of dairy cattle fertility: A review. Biotechnol. Agron. Soc. Environ. 17:64-75.

Beavers, L., and B. Van Doormaal. 2016. Selection for increased resistance to metabolic diseases. The Bullvine. Accessed Jan. 16, 2021. https://www.thebullvine.com/news/selection-for-increased -resistance-to-metabolic-diseases/.

Berry, D. P. 2013. Breeding strategies to reduce environmental footprint in dairy cattle. Adv. Anim. Biosci. 4(Suppl. 1):28-36. https: //doi.org/10.1017/S2040470013000289.

Berry, D. P., N. C. Friggens, M. Lucy, and J. R. Roche. 2016. Milk production and fertility in cattle. Annu. Rev. Anim. Biosci. 4:269-290. https://doi.org/10.1146/annurev-animal-021815-111406.

Berry, D. P., A. J. Twomey, R. D. Evans, A. R. Cromie, and S. C. Ring. 2019. Heritability - what is it, and what is it not; implications for improving cattle health. Cattle Pract. 27:1-11.

Boettcher, P. J., J. C. M. Dekkers, and B. W. Kolstad. 1998. Development of an udder health index for sire selection based on somatic cell score, udder conformation, and milking speed. J. Dairy Sci. 81:1157-1168. https://doi.org/10.3168/jds.S0022-0302(98)75678 -4 .

Bohren, B. B., W. G. Hill, and A. Robertson. 1966. Some observations on asymmetrical correlated responses to selection. Genet. Res. 7:44-57. https://doi.org/10.1017/S0016672300009460.

Cai, Z., M. Dusza, B. Guldbrandtsen, M. S. Lund, and G. Sahana. 2020. Distinguishing pleiotropy from linked QTL between milk production traits and mastitis resistance in Nordic Holstein cattle. Genet. Sel. Evol. 52:19. https://doi.org/10.1186/s12711-020-00538 $-6$.

Canadian Dairy Network. 2021. Lifetime Performance Index (LPI) Formula. Accessed Apr. 16, 2021. https://www.cdn.ca/document .php?id $=443$.

Cassell, B. 2009. Using heritability for genetic improvement. Virginia Cooperative Extension publication, 404-084. Accessed Apr. 16, 2021. www.pubs.ext.vt.edu/404/404-084/404-084.html.

Canadian Dairy Information Center. 2019. Canadian Dairy Information Center. Accessed September 24, 2020. www.dairyinfo.gc.ca.

Cesarani, A., I. Pocrnic, N. P. P. Macciotta, B. O. Fragomeni, I. Misztal, and D. A. L. Lourenco. 2019. Bias in heritability estimates from genomic restricted maximum likelihood methods under different genotyping strategies. J. Anim. Breed. Genet. 136:40-50. https://doi.org/10.1111/jbg.12367.
Cheverud, J. M. 1988. A comparison of genetic and phenotypic correlations. Evolution 42:958-968. https://doi.org/10.1111/j.1558 -5646.1988.tb02514.x.

Falconer, D. S. 1981. Introduction to Quantitative Genetics. Longman.

Fleming, A., C. F. Baes, A. A. A. Martin, T. C. S. Chud, F. Malchiodi, L. F. Brito, and F. Miglior. 2019. Symposium review: The choice and collection of new relevant phenotypes for fertility selection. J. Dairy Sci. 102:3722-3734. https://doi.org/10.3168/jds.2018-15470.

Fleming, A., G. Kistemaker, and B. Van Doormaal. 2020. Investigation of Phenotypic Trends and Sire Proof Interpretation for Select Functional Traits. Lactanet Canada.

Forni, S., I. Aguilar, and I. Misztal. 2011. Different genomic relationship matrices for single-step analysis using phenotypic, pedigree and genomic information. Genet. Sel. Evol. 43:1. https://doi.org/ 10.1186/1297-9686-43-1.

Guarini, A. R., D. A. L. Lourenco, L. F. Brito, M. Sargolzaei, C. F. Baes, F. Miglior, I. Misztal, and F. S. Schenkel. 2019. Genetics and genomics of reproductive disorders in Canadian Holstein cattle. J. Dairy Sci. 102:1341-1353. https://doi.org/10.3168/jds.2018-15038.

Haile-Mariam, M., and J. E. Pryce. 2019. Genetic evaluation of gestation length and its use in managing calving patterns. J. Dairy Sci. 102:476-487. https://doi.org/10.3168/jds.2018-14981.

Hayes, B. J. 1998. Heritability of temperament in Canadian Holsteins. Pages 391-394 in 6th World Congr. Genet. Appl. Livest. Prod., Armidale, Australia.

Heringstad, B., C. Egger-Danner, N. Charfeddine, J. E. Pryce, K. F. Stock, J. Kofler, A. M. Sogstad, M. Holzhauer, A. Fiedler, K. Müller, P. Nielsen, G. Thomas, N. Gengler, G. de Jong, C. Ødegård, F. Malchiodi, F. Miglior, M. Alsaaod, and J. B. Cole. 2018. Invited review: Genetics and claw health: Opportunities to enhance claw health by genetic selection. J. Dairy Sci. 101:4801-4821. https:// doi.org/10.3168/jds.2017-13531.

Heringstad, B., G. Klemetsdal, and J. Ruane. 2000. Selection for mastitis resistance in dairy cattle: A review with focus on the situation in the Nordic countries. Livest. Prod. Sci. 64:95-106. https://doi .org/10.1016/S0301-6226(99)00128-1.

Jamrozik, J., J. Fatehi, G. J. Kistemaker, and L. R. Schaeffer. 2005. Estimates of genetic parameters for Canadian Holstein female reproduction traits. J. Dairy Sci. 88:2199-2208. https://doi.org/10 .3168/jds.S0022-0302(05)72895-2.

Jamrozik, J., A. Koeck, G. J. Kistemaker, and F. Miglior. 2016. Multiple-trait estimates of genetic parameters for metabolic disease traits, fertility disorders, and their predictors in Canadian Holsteins. J. Dairy Sci. 99:1990-1998. https://doi.org/10.3168/jds .2015-10505.

Jamrozik, J., and L. R. Schaeffer. 1997. Estimates of genetic parameters for a test day model with random regressions for yield traits of first lactation Holsteins. J. Dairy Sci. 80:762-770. https://doi .org/10.3168/jds.S0022-0302(97)75996-4.

Jenkins, G. M., P. Amer, K. Stachowicz, and S. Meier. 2016. Phenotypic associations between gestation length and production, fertility, survival, and calf traits. J. Dairy Sci. 99:418-426. https://doi .org/10.3168/jds.2015-9934.

Kadarmideen, H. N., R. Thompson, M. P. Coffey, and M. A. Kossaibati. 2003. Genetic parameters and evaluations from single- and multiple-trait analysis of dairy cow fertility and milk production. Livest. Prod. Sci. 81:183-195. https://doi.org/10.1016/S0301 -6226(02)00274-9.

Koeck, A., S. Loker, F. Miglior, D. F. Kelton, J. Jamrozik, and F. S. Schenkel. 2014. Genetic relationships of clinical mastitis, cystic ovaries, and lameness with milk yield and somatic cell score in first-lactation Canadian Holsteins. J. Dairy Sci. 97:5806-5813. https://doi.org/10.3168/jds.2013-7785.

Koeck, A., F. Miglior, D. F. Kelton, and F. S. Schenkel. 2012a. Short communication: Genetic association of body condition score with disease resistance in first lactation Canadian Holsteins. Can. J. Anim. Sci. 92:285-289. https://doi.org/10.4141/cjas2012-047.

Koeck, A., F. Miglior, D. F. F. Kelton, and F. S. S. Schenkel. 2012b. Health recording in Canadian Holsteins: Data and genetic parameters. J. Dairy Sci. 95:4099-4108. https://doi.org/10.3168/jds.2011 -5127 . 
Koots, K. R., and J. P. Gibson. 1996. Realized sampling variances of estimates of genetic parameters and the difference between genetic and phenotypic correlation. Genetics 143:1409-1416.

Kramer, M., M. Erbe, B. Bapst, A. Bieber, and H. Simianer. 2013. Estimation of genetic parameters for novel functional traits in Brown Swiss cattle. J. Dairy Sci. 96:5954-5964. https://doi.org/10.3168/ jds.2012-6236.

Lassen, J., and T. Mark. 2008. Short Communication: Genotype by housing interaction for conformation and workability traits in Danish Holsteins. J. Dairy Sci. 91:4424-4428. https://doi.org/10 $.3168 /$ jds.2008-1116.

Loker, S., C. Bastin, F. Miglior, A. Sewalem, L. R. Schaeffer, J. Jamrozik, A. Ali, and V. Osborne. 2012. Genetic and environmental relationships between body condition score and milk production traits in Canadian Holsteins. J. Dairy Sci. 95:410-419. https://doi .org/10.3168/jds.2011-4497.

Malchiodi, F., J. Jamrozik, A.-M. Christen, A. Fleming, G. J. Kistemaker, C. Richardson, V. Daniel, D. F. Kelton, F. S. Schenkel, and F. Miglior. 2020. Symposium review: Multiple-trait single-step genomic evaluation for hoof health. J. Dairy Sci. 103:5346-5353. https://doi.org/10.3168/jds.2019-17755.

Malchiodi, F., A. Koeck, S. Mason, A. M. Christen, D. F. Kelton, F. S. Schenkel, and F. Miglior. 2017. Genetic parameters for hoof health traits estimated with linear and threshold models using alternative cohorts. J. Dairy Sci. 100:2828-2836. https://doi.org/10.3168/jds .2016-11558.

Martin, P., C. Baes, K. Houlahan, C. Richardson, J. Jamrozik, and F. Miglior. 2019. Genetic correlations among selected traits in Canadian Holsteins. Can. J. Anim. Sci. 99:693-704. https://doi.org/10 $.1139 /$ cjas-2018-0190.

Meyer, K., and E. B. Burnside. 1987. Scope for a subjective assessment of milking speed. J. Dairy Sci. 70:1061-1068. https://doi.org/10 .3168/jds.S0022-0302(87)80112-1.

Miglior, F., A. Fleming, F. Malchiodi, L. F. Brito, P. Martin, and C. F. Baes. 2017. A 100-Year Review: Identification and genetic selection of economically important traits in dairy cattle. J. Dairy Sci. 100:10251-10271. https://doi.org/10.3168/jds.2017-12968.

Miglior, F., A. Sewalem, J. Jamrozik, J. Bohmanova, D. M. Lefebvre, and R. K. Moore. 2007. Genetic analysis of milk urea nitrogen and lactose and their relationships with other production traits in Canadian Holstein cattle. J. Dairy Sci. 90:2468-2479. https://doi .org/10.3168/jds.2006-487.

Misztal, I., S. Tsuruta, T. Strabel, B. Auvray, T. Druet, and D. H. Lee. 2002. BLUPF90 and related programs (BGF90). Proc. 7th World Congr. Genet. Appl. Livest. Prod. 1-2.

Moore, R. K., B. W. Kennedy, L. R. Schaeffer, and J. E. Moxley. 1990. Relationships between reproduction traits, age and body weight at calving, and days dry in first lactation Ayrshires and Holsteins. J. Dairy Sci. 73:835-842. https://doi.org/10.3168/jds .S0022-0302(90)78737-1.

Nayeri, S., F. S. Schenkel, P. Martin, A. Fleming, J. Jamrozik, F. Malchiodi, L. F. Brito, C. F. Baes, M. Sargolzaei, and F. Miglior. 2020. Estimation of genetic parameters for mid-infrared-predicted lactoferrin and milk fat globule size in Holstein cattle. J. Dairy Sci. 103:2487-2497. https://doi.org/10.3168/jds.2019-16850.

Negussie, E., I. Strandén, and E. A. Mäntysaari. 2008. Genetic analysis of liability to clinical mastitis, with somatic cell score and production traits using bivariate threshold-linear and linear-linear models. Livest. Sci. 117:52-59. https://doi.org/10.1016/j.livsci 2007.11.009.

Neuenschwander, T. F. O., F. Miglior, J. Jamrozik, O. Berke, D. F. Kelton, and L. R. Schaeffer. 2012. Genetic parameters for producer-recorded health data in Canadian Holstein cattle. Animal 6:571-578. https://doi.org/10.1017/S1751731111002059.
Norman, H. D., J. R. Wright, and R. H. Miller. 2011. Potential consequences of selection to change gestation length on performance of Holstein cows. J. Dairy Sci. 94:1005-1010. https://doi.org/10 $.3168 /$ jds.2010-3732.

Oliveira, G. A. Junior, L. R. Schaeffer, F. Schenkel, F. Tiezzi, and C. F. Baes. 2021. Potential effects of hormonal synchronized breeding on genetic evaluations of fertility traits in dairy cattle: A simulation study. J. Dairy Sci. 104:4404-4412. https://doi.org/10.3168/ jds.2020-18944.

Pritchard, T., M. Coffey, R. Mrode, and E. Wall. 2013. Genetic parameters for production, health, fertility and longevity traits in dairy cows. Animal 7:34-46. https://doi.org/10.1017/ S1751731112001401.

Pryce, J. E., M. P. Coffey, and S. Brotherstone. 2000. The genetic relationship between calving interval, body condition score and linear type and management traits in registered Holsteins. J. Dairy Sci. 83:2664-2671. https://doi.org/10.3168/jds.S0022-0302(00)75160 -5 .

Pryce, J. E., M. P. Coffey, and G. Simm. 2001. The relationship between body condition score and reproductive performance. J. Dairy Sci. 84:1508-1515. https://doi.org/10.3168/jds.S0022 -0302(01)70184-1.

Pryce, J. E., R. F. Veerkamp, R. Thompson, W. G. Hill, and G. Simm. 1997. Genetic aspects of common health disorders and measures of fertility in Holstein Friesian dairy cattle. Anim. Sci. 65:353-360. https://doi.org/10.1017/S1357729800008559.

Sewalem, A., G. J. Kistemaker, and F. Miglior. 2010. Relationship between female fertility and production traits in Canadian Holsteins. J. Dairy Sci. 93:4427-4434. https://doi.org/10.3168/jds .2009-2915.

Sewalem, A., G. J. Kistemaker, and B. J. Van Doormaal. 2002. Bayesian inferences for milking temperament in Canadian Holsteins. Pages $0-3$ in 7 th World Congr. Genet. Appl. Livest. Prod., Montpellier, France.

Sewalem, A., F. Miglior, and G. J. Kistemaker. 2011. Short communication: Genetic parameters of milking temperament and milking speed in Canadian Holsteins. J. Dairy Sci. 94:512-516. https://doi .org/10.3168/jds.2010-3479.

Shin, E.-K., J.-K. Jeong, I.-S. Choi, H.-G. Kang, T.-Y. Hur, Y.-H. Jung, and I.-H. Kim. 2015. Relationships among ketosis, serum metabolites, body condition, and reproductive outcomes in dairy cows. Theriogenology 84:252-260. https://doi.org/10.1016/j .theriogenology.2015.03.014.

Steinbock, L., A. Näsholm, B. Berglund, K. Johansson, and J. Philipsson. 2003. Genetic effects on stillbirth and calving difficulty in Swedish Holsteins at first and second calving. J. Dairy Sci. 86:2228-2235. https://doi.org/10.3168/jds.S0022-0302(03)73813 -2 .

Van Doormaal, B. 2007. Selection for improved fertility and calving performance. Can. Dairy Netw. 3.

Van Dorp, T. E., P. Boettcher, and L. R. Schaeffer. 2004. Genetics of locomotion. Livest. Prod. Sci. 90:247-253. https://doi.org/10 .1016/j.livprodsci.2004.06.003.

Veerkamp, R. F., H. A. Mulder, R. Thompson, and M. P. L. Calus. 2011. Genomic and pedigree-based genetic parameters for scarcely recorded traits when some animals are genotyped. J. Dairy Sci 94:4189-4197. https://doi.org/10.3168/jds.2011-4223.

Veerkamp, R. F., and R. Thompson. 1999. Multi-trait covariance functions to estimate genetic correlations between milk yield, dry-matter intake and live weight during lactation. BSAP Occasional Publication 24:147-151. https://doi.org/10.1017/S1463981500043168.

Walsh, B., and M. Lynch. 2018. Evolution and Selection of Quantitative Traits. Oxford University Press. 